\title{
Mujeres excombatientes y transformación de conflictos: paradojas de la construcción de la paz en la lucha armada*
}

\author{
Ex-combatant women and conflicts transformation: \\ paradoxes of the peacebuilding in the armed struggle
}

\author{
Andrea Marcela Barrera Téllez** \\ Universidad París Diderot, París, Francia.
}

Recibido: 7 de febrero de 2018. Aprobado: 28 de junio de 2018.

DOI: $10.25100 /$ lamanzanadeladiscordia.v13i2.6730

Artículo de investigación

Resumen: La participación de las mujeres en el conflicto armado colombiano como combatientes suele ser un fenómeno social frecuentemente desconocido; más aún, los motivos políticos que están en el centro de la militancia de muchas de ellas parecen estar invisibilizados, gracias a una idea hegemónica según la cual ellas o bien son extremadamente crueles y violentas, o bien son víctimas pasivas de un conflicto que les ha sido completamente impuesto. Este texto busca explorar las motivaciones políticas de la militancia de las mujeres en los grupos armados insurgentes y, en general, de su participación en la lucha armada en el país. Por esta razón, se presta una atención especial a las voces, los relatos, las reflexiones y los análisis de mujeres excombatientes con quienes hemos podido hablar o a quienes hemos tenido la oportunidad de leer, y que proponen perspectivas novedosas sobre la relación entre la guerra, la lucha armada, la transformación de los conflictos y la paz.

Palabras clave: Investigación sobre la paz; conflicto político; conflicto armado; mujeres políticas.
Abstract: The women's participation in the Colombian armed conflict as combatants is a social phenomenon frequently unknown; furthermore, the political motives that are in the center of the militancy, for too many of them, seem to be invisibles because of a hegemonic idea according to which they are extremely cruel and violent women, or they are passive victims of a conflict that has been completely imposed on them. This text wants to explore the political motivations of women's militancy in insurgent armed groups and, in general, of their participation in the armed struggle in the country. For this reason, a special attention is provided to the ex-combatant women's voices, stories, reflections and analysis, women with whom we have talked and that we have had the opportunity to read, and who purpose original perspectives about the relationship between the war, the armed struggle, the conflicts transformation and the peace.

Keywords: Peace research; political conflict; armed conflict; women in politics.

* El presente escrito es un artículo de reflexión producto de la investigación desarrollada por la autora en el marco de sus estudios de maestría entre 2012 y 2014, titulada "Eso no es que en un momento empezamos a buscar la paz, no, siempre, desde siempre, las excombatientes colombianas y la paz", desarrollada bajo la dirección de la profesora Geneviève Pruvost para optar al título de Master en Ciencias Sociales, mención Sociología. De manera más amplia, el artículo se inscribe en el trabajo que la autora ha venido desarrollando con mujeres excombatientes, especialmente de grupos armados insurgentes, hasta la actualidad.

** Estudiante de doctorado en Sociología y Estudios de género, en la Universidad Paris Diderot. Master en ciencias sociales, mención en sociología, especialidad en género, política y sexualidades de la EHESS. Integrante del grupo de investigación en Teorías Políticas Contemporáneas de la Universidad Nacional de Colombia y del grupo de estudios en Subjetivaciones Políticas -SuPo-

Correo electrónico: andrea.barrera@etu.univ-paris-diderot.fr. 
El 5 de agosto de 2015 se llevó a cabo en Bogotá el conversatorio Aprendizajes y retos para los procesos de desarme, desmovilización y reintegración de mujeres combatientes, organizado con el apoyo de Fokus por la Red Nacional de Mujeres Excombatientes de la Insurgencia, la Corporación Humanas y la Secretaría Distrital de la Mujer. El conversatorio, moderado por Luz Piedad Caicedo, subdirectora de Humanas, contó con la participación de seis mujeres excombatientes del Movimiento Armado Quintín Lame-MAQL-, de las Autodefensas Unidas de Colombia -AUC-, del Ejército de Liberación Nacional -ELN-, del Movimiento 19 de Abril -M19-, del Ejército Popular de Liberación -EPL-, y de las Fuerzas Armadas Revolucionarias de Colombia, Ejército del Pueblo -FARC-EP- (Corporación Humanas, 2015, p. 5).

En diferentes momentos de este conversatorio, varias de las excombatientes afirmaron ser "sujetas políticas". Así, por ejemplo, M. Criado afirmó: "Indudablemente, entonces, que el primer planteamiento es que seamos reconocidas como sujetas politicas, casi como primera condición, convirtiéndose en el presupuesto básico de todos los planes y proceso de reintegración de mujeres"' (Corporación Humanas, 2015, p. 22).

Considero que esta reivindicación es central para el análisis de la participación de las mujeres en el conflicto armado colombiano, pues constituye un llamado tanto al reconocimiento de la existencia de las mujeres combatientes y excombatientes, como del carácter político de su militancia y de su participación en la lucha armada. Este llamado permite, cuando menos, cuestionar la idea hegemónica según la cual las mujeres que han participado de las insurgencias colombianas lo han hecho 1) porque han sido engañadas o reclutadas a la fuerza por los guerreros, aparentemente únicos y verdaderos implicados en el conflicto armado; o 2) porque son mujeres cuya supuesta "naturaleza femenina" ha salido de control y las ha llevado no sólo a querer tomar las armas, que en teoría no les corresponden, sino que además ejercen la violencia de manera monstruosa e ilimitada.
Más aún, este llamado permite hacer frente al desconocimiento recurrente, por no decir sistemático, que existe frente a la participación de las mujeres en el conflicto armado como combatientes, en donde las excepciones vendrían a "confirmar la regla". Así, por ejemplo, se habla de mujeres "muy crueles" como Karina, apodada por los medios de comunicación como "la Rambo de las FARC"2, pues, se dijo, producía terror entre los combatientes a quienes comandaba y entre las comunidades a las que llegaba el frente del que hacía parte, debido a la violencia desbordada que ejercía continuamente. El país ha escuchado también el nombre de Sandra Ramírez, la combatiente de las FARC-EP que firmó el preacuerdo que inauguró oficialmente la negociación que condujo a la firma del Acuerdo Final para la Terminación del Conflicto y la Construcción de una Paz Estable y Duradera. Sin embargo, de Ramírez no se habló tanto por su participación activa en estas negociaciones, sino por haber sido la compañera de Manuel Marulanda Vélez, es decir, que no se habla de ella como combatiente que hizo parte de los primeros acercamientos que produjeron el acuerdo entre las FARC-EP y el gobierno colombiano, sino como la pareja de quien fuera una de las principales figuras del grupo armado (Corporación Humanas, 2015, p. 11).

En estos casos se habla de mujeres específicas por su "crueldad sin límites" o por sus relaciones sentimentales, lo que, sin embargo, resulta ser más una excepción que una regla porque, como afirmaba anteriormente, cuando se hace referencia a la generalidad de las mujeres que han hecho parte de los grupos armados, normalmente se habla de ellas como víctimas del reclutamiento forzado, del engaño del que han sido víctimas y que las llevó a ingresar a los grupos armados y/o de la anticoncepción forzada (un tema de "moda" que ha ocupado espacios importantes en los noticieros a nivel nacional, especialmente en RCN y en programas de televisión de la cadena NTN24), esto es, de abortos realizados contra su voluntad y en condiciones insalubres.

Las historias, muchas veces anónimas y otras pocas veces "personalizadas", a las que acabamos de hacer referencia, muestran bien la dualidad

El uso de formato itálica ha sido escogido por la autora.

2 Para ampliar la información, véase Se entregó la temible 'Karina' de las Farc: http://www.eltiempo.com/archivo/documento/MAM-2941324. 
característica de las representaciones de las combatientes y las excombatientes en el conflicto armado colombiano: de un lado, tenemos la imagen de mujeres "monstruosas" que ejercen una violencia ilimitada como producto de una "naturaleza femenina" excesiva o impulsiva (Cardi y Pruvost, 2012) o de una "desnaturalización" que abre paso a su deshumanización (Boutron, 2012), mientras que, del otro lado, tenemos una idea de las mujeres como víctimas del "terrorismo" o de los hombres armados (Lara, 2000) que las utilizan en beneficio de sus propios intereses individuales.

Estas representaciones dicotómicas constituyen una idea de la mujer (ex)combatiente según la cual sólo puede ser un "semi-monstruo" o una víctima inmóvil de una guerra que le ha sido impuesta por los guerreros. Esta es la idea que se va construyendo, es necesario insistir en ello, con base en los pocos casos conocidos de mujeres que han hecho parte de algún grupo armado. Por el contrario, en la mayor parte de los casos, hay una negación deliberada de la existencia de estas mujeres que se traduce en la más absoluta obliteración de sus experiencias.

Existe, entonces, al menos un doble desconocimiento, entendido como la ausencia de (re)conocimiento, de las mujeres excombatientes: el primero, en términos de su existencia misma y de los papeles que han desempeñado en la historia de la sociedad colombiana, y el segundo, en relación con sus prácticas como sujetas políticas, desconocimiento que hunde sus raíces en la negación del carácter político tanto de las organizaciones insurgentes como de la participación de las mujeres en la lucha armada. Al respecto, María Vásquez nos dice:

Tras los acuerdos de paz de los años 90 al 97, la mayoría de mujeres protagonistas políticas y militares durante los años de guerra, desaparecieron del escenario público. Tan sólo diez años después, un grupo de mujeres de diversas organizaciones insurgentes comenzamos a reflexionar sobre lo que significó incursionar en el mundo de la guerrilla y luego, cuáles fueron las principales dificultades del retorno a la vida civil y la reconstrucción de nuestros proyectos de vida en una perspectiva de paz. Ese colectivo, con sus altibajos, todavía se mantiene. Mi propuesta se orienta a propiciar la reflexión sobre el carácter de las insurgentas como sujetas políticas en el concierto del trabajo por construir la paz evaluando su opción por la no violencia. Me pregunto, ¿aceptará el movimiento de mujeres por la paz que participemos en la construcción de una agenda común? ¿Nos reconocerá como sujetas políticas el movimiento popular? (Vásquez, 2014, s.p.).

Esta propuesta, que es la de María Vásquez y la de otras excombatientes, me parece de importancia capital. En efecto, las reflexiones y las "lecciones aprendidas" por estas mujeres que vivieron en "carne propia" el conflicto armado, que tuvieron y tienen proyectos y apuestas políticas que han puesto a jugar y desplegado en diversos escenarios, nos pueden enseñar mucho como sociedad: mucho de lo que somos y no queremos ver, mucho de lo que está en juego aunque parezca banal en la cotidianidad, mucho de lo que "cuesta" la paz (aunque esta sea, de seguro, una aproximación inconveniente) y también de lo que podemos ganar en el camino de su búsqueda y construcción, mucho de lo que ha hecho que los conflictos en Colombia procuren ser resueltos por la violencia y de los efectos de esta situación; mejor dicho, las excombatientes nos pueden enseñar mucho de nosotras mismas (hombres y mujeres colombianas), de quienes somos, de quienes hemos sido, de quienes podemos ser.

Este texto hace parte del esfuerzo por aprender desde y con las mujeres excombatientes y por avanzar reflexiones sobre la violencia, los conflictos y la construcción de la paz en el país. En ese sentido, este ejercicio se desarrolló desde lo que podríamos denominar un enfoque de género, en la medida en que busca, de un lado, indagar en la historia de las mujeres en el marco del conflicto armado contemporáneo en Colombia y, de otro, de manera ciertamente exploratoria, busca comprender el carácter social de las actividades de las mujeres al interior de los grupos armados y como excombatientes. Esto pues, a partir del enfoque de género,

en lugar de ignorar, marginar, borrar, hacer invisible, olvidar o incluso deliberada y abiertamente discriminar el quehacer de las mujeres en el mundo, se busca indagar en dónde están y qué hacen o no hacen, y por qué. Además, nos permite entender la conflictiva relación entre los géneros y, por lo tanto, comprender mejor el quehacer de los hombres 
quienes no están solos en este planeta. [...] [Ahora bien,] tampoco es que ahora haya que reivindicar lo que hacen las mujeres como necesariamente significativo y fundamental a priori. Sin embargo, a partir de lo que se ha visto y estudiado durante algunas décadas, hoy se pueden emitir juicios que hacen tambalear muchos cimientos del pensamiento androcéntrico. Por ejemplo, se ha visto que al estudiar la acción de las mujeres no podemos seguir tomando únicamente en consideración el terreno de la política formal, la realpolitik, sino que es fundamental que las "nuevas" formas de hacer política por parte de las mujeres, formas sui generis de organización y de lucha, como las acciones de barrio y desde la vida cotidiana, sean consideradas (Bartra, 2010, pp. 75-76).

Así, el presente artículo es el resultado de algunas de las reflexiones que he tratado de avanzar en los últimos años sobre la existencia, el reconocimiento, los saberes, los conocimientos y, sobre todo, los proyectos políticos de las mujeres que han participado de la lucha armada en el país. Buena parte de lo que aquí procuro desarrollar ha tenido lugar en el contexto de mis estudios, de las búsquedas documentales que he hecho y, especialmente, de las conversaciones que he podido tener con mujeres excombatientes que son, sobre todo, mujeres comprometidas con la paz en Colombia cuya generosidad me ha permitido, a pesar de las dificultades propias de estos escenarios, acercarme un poco a sus pensamientos y sueños de transformación de las realidades en las que vivimos. En ese sentido, mucho de lo aquí "dicho" son ideas en constante transformación, respuestas liminares a preguntas complejas, pequeños frutos que he(mos) ido recogiendo a lo largo del camino que se recorre cuando se piensa y se cree en la posibilidad de construir nuevos mundos y en el deseo de contribuir, de alguna manera, a esos mundos que muchas veces ya están siendo.

En ese mismo sentido, es preciso aclarar que no es mi intención hablar de las experiencias de todas las mujeres excombatientes, ni del lugar de la mujer excombatiente en la construcción de paz, como si existiera ese sujeto único e indivisible y, en consecuencia, un único lugar que pudiera ocupar en los procesos de construcción de paz. Más aún, me parece importante retomar las palabras y reflexiones de mujeres que dejaron de hacer parte de los grupos armados hace varios años, especialmente en el caso de las mujeres que militaron en el M-19, para dar cuenta de los procesos y de las acciones que han desarrollado en sus experiencias excombatientes.

En efecto, los relatos con base en los cuales se ha construido este texto corresponden a las palabras de mujeres que han dejado de ser combatientes desde hace algunos años y llegando incluso a períodos de un par de décadas, en los casos de quienes salieron de las insurgencias en la década de 1990. Esta distancia con la participación en las insurgencias como combatientes constituyó un criterio de reflexión importante, pues me permitió escuchar las voces de quienes ya habían pasado por las instituciones del Estado con sus programas de reintegración; de quienes han tenido la oportunidad, en el caso de algunas de ellas, de encontrarse y organizarse con otras mujeres excombatientes; de quienes hablan de aquello que vivieron dentro de los grupos armados con una perspectiva formada, en parte, por el hecho de saber que la guerrilla a la que pertenecieron ya no existe más (y saben cómo ocurrió ese proceso de desmovilización y de reintegración, incluyendo, por ejemplo, el asesinato de sus excompañeros y excompañeras, como ocurrió con el M-19 y el asesinato de Carlos Pizarro, por sólo mencionar uno) o que, de existir (como en el caso del ELN), su decisión de no seguir haciendo parte del grupo insurgente se ha "sedimentado" y ha sido reinterpretada con base en las experiencias como mujeres excombatientes. Esto explica que las voces de las mujeres farianas que han salido de la lucha armada en el marco del acuerdo de paz negociado en la Habana entre 2012 y 2016 no aparezcan en el texto de manera central; sin embargo, aparecerán a lo largo del texto gracias a documentos que han sido publicados por ellas como parte de un esfuerzo por visibilizar su lucha; rescatar las pequeñas y grandes historias de sus compañeras y compañeros de lucha, junto a las de otras mujeres revolucionarias; compartir su visión y nutrirse de otras experiencias y saberes ${ }^{3}$.

3 Para ampliar la información, véase la declaración pública escrita por guerrilleras de las FARC-EP: http://mujerfariana.org/vision/ declaraciones/75-declaracion.html 
En términos metodológicos, cabe anotar que hace un par de años, a finales de 2013, tuve la oportunidad de entrevistar a catorce excombatientes, ocho mujeres y seis hombres, que habían participado de grupos armados guerrilleros y paramilitares (guerrillas: M-19, FARC-EP; paramilitares: AUC). Ninguna de las mujeres entrevistadas hizo parte de un grupo paramilitar. Con ellas, tuve encuentros en los que sostuvimos entrevistas de relatos de vida, de modo que con todas ellas se conversó sobre sus familias, sus infancias, su entrada a los grupos insurgentes, su paso por ellos, sobre aquello que han hecho tras su salida de las guerrillas y, en particular, sobre aquello que consideran que es la paz desde sus experiencias como mujeres excombatientes. Las edades de estas mujeres oscilaban, en el momento de las entrevistas, entre los 25 y los 48 años; en el caso de quienes hicieron parte del M-19, las edades se encontraban entre los 43 y los 48 años, mientras que las mujeres que habían estado en las FARC-EP tenían entre 25 y 30 años. Los extractos de entrevistas que se encuentran citados en el presente artículo, corresponden a los diálogos que sostuve con estas mujeres entre octubre y noviembre de 2013. Todas las mujeres que militaron en las FARC-EP con quienes tuve la oportunidad de conversar, fueron contactadas por medio de la ACR (en ese momento, Agencia Colombiana para la Reintegración), mientras que las mujeres que habían militado en el M-19 las encontré gracias a contactos personales. Además de las entrevistas, este texto se nutre de las palabras de mujeres excombatientes del M-19, especialmente del trabajo publicado por Vera Grabe, excombatiente del M-19, producto de su tesis doctoral a propósito de la paz en la historia de este movimiento armado, así como de los textos escritos por varias excombatientes en la revista $\mathrm{La}^{3} 3^{4}$, un proyecto de construcción de ciudadanías activas para la paz desde la Red Nacional de Mujeres Excombatientes de la Insurgencia. Así pues, todo el texto está construido con base en la recolección y la interpretación de material cualitativo relacionado con la participación de las mujeres en el conflicto armado colombiano como combatientes y como constructoras de paz, confiriéndole particular atención al carácter político de dicha participación, asunto generalmente descuidado o ignorado tanto en la academia como en los relatos hegemónicos que circulan socialmente al respecto.

El presente texto se encuentra dividido en tres secciones. La primera está dedicada a una rápida revisión de los motivos que, según diversos textos y trabajos, han tenido las mujeres excombatientes para ingresar a los grupos guerrilleros. Es preciso aclarar en este punto que en este texto hago referencia a las "mujeres excombatientes" para "señalar" el hecho que ellas combatieron dentro de algún grupo subversivo y que ya no participan de la lucha armada, sin embargo, es evidente que estas mujeres no solo son excombatientes. Como mostraré, ellas son mujeres que han tenido apuestas de construcción de paz y de transformación social; sus vidas son entramados complejos de experiencias, vivencias, alegrías, tristezas, apuestas, obstáculos, sueños, palabras dichas, silencios que hablan y callan. Y dada esta complejidad, propongo, en esta primera parte, atender al hecho que, contrario al discurso hegemónico que aparece en los medios de comunicación y en algunas de las políticas estatales, algunas mujeres en Colombia han decidido hacer parte de la lucha armada por razones de orden político, esto es, con la firme convicción de que la sociedad colombiana adolece de graves problemas políticos, sociales y económicos. En ese sentido, en la segunda parte trataré de demostrar que la militancia y la pertenencia a los grupos armados revolucionarios, constituyeron para algunas mujeres escenarios en los que podían desplegar sus apuestas de transformación de los conflictos que consideraban (y pueden seguir considerando) centrales en términos de la injusticia social y de la necesidad de construir una paz amplia y dialogada. Finalmente, en la tercera parte, procuro mostrar que las experiencias "excombatientes" de estas mujeres han estado guiadas por la continuidad en la búsqueda de la paz, esta vez desde acciones políticas individuales y colectivas que implican la recuperación de la memoria, la organización en torno a objetivos comunes, el reposicionamiento de las experiencias de las mujeres que han participado de las luchas por

4 Para ampliar la información, véase revista La13, publicación de la Red Nacional de Mujeres Excombatientes de la Insurgencia: http:// www.revistala13.com/numeros.html 
las transformaciones sociales y de la lucha armada en la sociedad colombiana y, sobre todo, reflexiones continuas sobre la paz, sus contenidos y los senderos que nos pueden conducir hacia ella o, mejor, el sendero que ella misma constituye hacia la vida.

\section{¿Por qué hacer parte de la lucha armada?: sobre los motivos de la militancia de las mujeres en los grupos armados insurgentes}

Para empezar a hablar de la participación de las mujeres en el conflicto armado colombiano es importante precisar, en primera instancia, que su entrada a los grupos armados no fue un proceso evidente o exento de obstáculos. En efecto, al momento de la creación de algunos grupos armados insurgentes, la cantidad de mujeres que estaban presentes y participaban era muy baja, cuando no inexistente.

Según B. Toro, existían dos argumentos principales para "sustentar" esta prohibición explícita o implícita, a saber, las dudas que recaían sobre las capacidades físicas de las mujeres para resistir a las difíciles condiciones que implica la lucha armada y, en segundo lugar, la idea más o menos generalizada según la cual la sexualidad de las mujeres podía ser, potencialmente, una fuente de desorden para los combatientes. Los procesos que permitieron que esos dos obstáculos fueran poco a poco superados, aunque fuera más o menos parcialmente, no han sido suficientemente estudiados, de modo que se trata de una historia pendiente (Londoño y Nieto, 2007), y de la cual no conocemos todavía sino pequeñas huellas.

En todo caso, es posible pensar esa transformación en, al menos, dos niveles: uno contextual y otro en términos de los motivos que llevaron a las mujeres a integrar las filas de los grupos guerrilleros. Dados los propósitos del presente escrito, no ahondaremos en el primer nivel. Baste, en todo caso, con mencionar que es posible identificar algunos fenómenos que pudieron, eventualmente, favorecer la "integración" de mujeres a los grupos armados insurgentes en el país. Así, por ejemplo, encontramos los procesos de emancipación (Londoño y Nieto, 2007) de las mujeres colombianas durante la segunda mitad del siglo XX, así como un contexto de movilización social y de polarización política que vivió la sociedad colombiana en este mismo período.

Los procesos de emancipación se inscriben, según diversas autoras, en un contexto regional de formación y consolidación del feminismo ${ }^{5}$. El papel de los movimientos feministas de la llamada "segunda ola" en América Latina (Lelièvre, Moreno y Ortíz, 2004), y de la comunidad académica interesada en los problemas y las realidades de las mujeres colombianas (Thomas, 1996), fueron centrales en este proceso. Tanto las unas como las otras lucharon por la adquisición de derechos fundamentales para las mujeres como, por ejemplo, el acceso a la educación, la participación en el mercado laboral y el cambio de los roles de género al interior de las familias y en espacios públicos (Lelièvre et al., 2004). Aunque estas reivindicaciones no necesariamente hayan generado cambios inmediatos ni tangibles (o, mejor, mesurables) en la sociedad colombiana, no es posible desconocer la existencia de "procesos de emancipación" que se vieron favorecidos por esta situación.

Frente al contexto de movilización social y de polarización política al que asistió la sociedad colombiana en la segunda mitad del siglo XX, es posible afirmar que se trató de un terreno fértil para la participación de las mujeres en la lucha armada. En efecto, es posible asegurar que las mujeres comenzaron a estar cada vez más presentes en los espacios públicos, profundamente marcados por la movilización social y, simultáneamente, por la represión estatal que buscaba eliminar cualquier forma de esta movilización. En consecuencia, la participación política de las mujeres se desarrolla, en este momento, en un contexto represivo (Rodríguez, 2008) y altamente antidemocrático ${ }^{6}$.

5 Según María Ibarra, el Primer Encuentro de Mujeres Latinoamericanas y del Caribe, llevado a cabo en Bogotá en 1981, fue un evento importante en el contexto de la participación de las mujeres en la lucha armada en Colombia (Ibarra, 2006).

6 Al respecto, cabe destacar que, si bien las mujeres obtuvimos el derecho al voto en 1954, lo que permitió que, en alguna medida, los partidos políticos tradicionales se constituyeran como nichos posibles de participación política para las mujeres, este paso fundamental hacia la ciudadanía de las colombianas no representó una apertura de hecho del sistema político colombiano. Al respecto, B. Rodríguez considera que la vía institucional no representó y no representa una oportunidad real de participación ni de representación para las mujeres y los hombres en el país, mientras que los grupos insurgentes se presentaron, en ese momento, como espacios posibles de participación política y de las luchas por la transformación del status-quo (Rodríguez, 2008). 
Ahora bien, frente al segundo nivel enunciado, los trabajos que tratan la participación de las mujeres en el conflicto armado en Colombia nos permiten identificar una serie de factores que influyeron en lo que podemos denominar las trayectorias militantes de las (ex)combatientes en el país. Dada la diversidad de los grupos armados colombianos, cada uno con relaciones particulares frente a sus militantes en función de sus dinámicos lineamientos político-militares, resulta difícil generalizar los motivos de la participación de las mujeres en ellos. En ese sentido, resulta, por lo menos, inadecuado procurar explicaciones que se reduzcan a un contexto (nacional, regional, local y/o por grupo armado) que haya sido más o menos favorable a este fenómeno social; asimismo, resulta insuficiente atender exclusivamente a las motivaciones de orden estrictamente personal e individual que pudieron tener lugar en el mismo, a pesar de resultar esenciales. Se trata más bien, en mi opinión, de una convergencia entre un contexto específico, una historia personal particular y motivaciones múltiples y diversas de cada mujer.

A pesar de la complejidad inherente a las motivaciones que se juegan en la decisión de ser parte de un grupo insurgente, es posible identificar algunas motivaciones de orden sociológico que son evocados frecuentemente por las excombatientes. Entre los factores que se pueden identificar en la literatura disponible (Lelièvre et al., 2004; Ibarra, 2006; Londoño y Nieto, 2007; Esguerra, 2013), están: 1) el gusto por la vida militar; 2) una situación anterior de violencia intrafamiliar; 3) la falta de perspectivas en la vida propia, a causa del desempleo y de la pobreza, o la búsqueda de seguridad, de trabajo, de alimento y de ropa; 4) la adhesión; 5) el deseo de venganza o los resentimientos personales; 6) el reclutamiento forzado; 7) el clima de movilización ; 8) el hecho de haber militado en otros grupos políticos o sociales; 9) el hecho de tener un compañero (no tanto así una compañera, o no por lo menos dentro de los estudios y testimonios que he podido conocer) y, de manera significativa, 10) el hecho de querer desafiar la autoridad masculina, frecuentemente encarnada por los padres y por los hermanos, y el orden familiar tradicional.

Como podemos observar, estos factores implican niveles diferentes de coerción y de limitaciones, de modo que es posible construir un continuum explicativo que iría de la incorporación más voluntaria a la menos voluntaria, en el cual la adhesión ideológica y el reclutamiento forzado constituirían los dos extremos. Es posible, en ese mismo sentido, encontrar situaciones intermedias en las que se mezclan, por ejemplo, la "atracción" por la militancia activa, un contexto específico de violencia y fenómenos estructurales como la pobreza.

En mis indagaciones, también he podido identificar una variedad de razones que llevaron a las mujeres a entrar a un grupo armado, particularmente, a grupos de guerrilla. Por ejemplo, el desempleo y las situaciones de violencia intrafamiliar que vivían las mujeres al interior de sus hogares, violencia que sus padres, madres y hermanos ejercían contra ellas, o la violencia a la que "asistían", generalmente del padre contra la madre, están en el centro de la decisión de irse y pedir el ingreso en la guerrilla para algunas mujeres. También están los casos de reclutamiento forzado que, sin embargo, en los casos que he podido conocer, tienen matices. Por ejemplo, Fernanda y Consuelo, excombatientes de las FARC-EP, fueron reclutadas por la fuerza, pero, según ellas mismas, esa no fue la única razón (lo cual no deja de causar un poco de sorpresa) para que entraran y, sobre todo, se mantuvieran dentro de la guerrilla; así, una de ellas menciona la insoportable situación de violencia intrafamiliar que vivía y la negativa inamovible de su padre para que ella pudiera ir a hacer su bachillerato en el pueblo con una beca que se había ganado; en el caso de la segunda mujer, su principal motivación fue evitar el desplazamiento forzado de su familia tras el asesinato de su padre por el mismo grupo armado al que ella entró, tras hacer una negociación con el comandante del grupo en esa zona. Como ella misma lo cuenta:

-A mi papá lo mató la guerrilla en el 99, él trabajaba en, sacaba oro, era minero. Eso y mi mamá nos cuidaba, no sé bien así...

- ¿Usted tenía cuántos años cuando su papá murió?

-16. Y de ahí pues, me fui por allá, me llevaron, mejor dicho, no me fui sino que me llevaron... Y ya así, allá en el grupo armado...

— ¿Eso pasó cuando usted tenía cuántos años?

-16, cuando matan a mi papá como a los 15 días me recogieron... Eso así... 
- ¿Y a usted ya le habían hablado del grupo o cómo pasa que usted se va?

—No, por ahí había mucho, o sea mantenía la guerrilla y matan a mi papá, entonces nos tocaba irnos, entonces nosotros no teníamos para dónde irnos y pues si éramos pobres mejor dicho. Entonces se hizo un acuerdo que yo me iba con ellos y mi familia se quedaba ahí en el pueblo, allá donde vivíamos. Eso fue.

A: ¿Fue como un acuerdo al que llegaron?

E: Sí, o sea, no tanto que llegamos sino que pues nos tocaba irnos entonces yo les dije "entonces ¿qué hacer? Entonces ¿yo me voy o qué para que mi mamá y mis hermanas no tengan que irse de acá?". Entonces sí, me fui con ellos en esa situación (Consuelo, comunicación personal, noviembre de 2013).

Algunas de las mujeres excombatientes con las que he hablado o que he leído, empezaron a militar dentro de un grupo de guerrilla por razones ideológicas. Ahora bien, esto no implica que se tratara de un único motivo, pero sí constituye la razón principal que evocan para dar cuenta de su decisión de ingresar o de no recular en su pertenencia al grupo armado que, en algunos casos, se dio de manera paulatina y sin un momento definitivo que marcara la entrada en el grupo armado. Así, por ejemplo, Lina dice a propósito de su entrada a las FARC-EP:

-Pues desde muy pequeñita, nosotros teníamos vínculos con ellos por lo mismo, por mi papá porque donde estaba mi papá, ellos llegaban, a la finca más que todo, mi papá trabajaba con ellos. Ellos le dejaban fincas para que mi papá revisara $\mathrm{y}$ todo, eso fue desde muy pequeñitos. Me llamaba como mucho la atención...

— ¿No te daba miedo?...

-No. Y entre los ideales que ellos el inculcaban a uno, a mí me parecían como bien, lo importante es que ellos luchan por una igualdad, por verlo a uno que no haya tanta pobreza, entonces todo eso como que llevaba a ellos. Y, cuando me vine para acá y dejé un tiempo así de, cuando mi hermano compró una finquita por aquí ... Y él me invitó que fuera por allá y yo subí con él y estaban ellos ahí, habían hartísimo, estaba [un frente], entonces ahí empecé ya con ellos, a estar con ellos otra vez y pues yo no tenía trabajo, estaba mal acá, tenía los dos niños pequeños, entonces me empezaron a mandarme, sí a mandarme a llevar intendencia, a hacerles mandados así bobos y me daban plata, hasta que una vez me dijo, un cucho, un comandante que ahorita está en la cárcel, me dijo que si yo quería trabajar con ellos, que él me pagaba, yo le dije que sí, que para los mandados, que para conseguir plata, llevarle gente, entonces le dije que sí y me daba un millón mensual. Entonces yo dije, no, pues de una. Entonces yo empecé, todo me parecía fácil, yo no le veía problema. No, alcancé a durar como un año trabajando así, hasta que estaba ahí en el campamento y ya pues que no, que tenía que durar 8, 15 días entonces. Pues yo feliz... (Lina, comunicación personal, noviembre 2013).

En las "tesis de mujer y género", que fueron construidas para el congreso constitutivo del naciente partido Farc, es posible encontrar una mención a la posibilidad que representó la lucha armada para las mujeres de una opción de vida diferente. Aquí yace -es posible pensarlo en esos términos- un reconocimiento de la diversidad de factores que pueden influir en términos de la decisión de entrar a hacer parte de un grupo armado insurgente como las FARC-EP. En efecto, en la primera tesis se puede leer: "el papel de las mujeres dentro de la organización armada ha sido fundamental en el nivel de desarrollo de nuestra lucha. FARC-EP fue para las mujeres rurales, especialmente, una opción de vida diferente, una oportunidad para escapar de una realidad de exclusión, discriminación y opresión" (Farianas, 2017). En ese sentido, la transformación de las vidas de esas mujeres se conjuga con la búsqueda de la transformación social, cuyas estructuras ha permeado las experiencias vitales, sobre todo de las mujeres rurales, como lo reconoce el mismo documento, muy probablemente debido a la profunda relación con el carácter marcadamente rural de una guerrilla como las FARC-EP.

Ahora bien, en términos de los motivos ideológicos que fueron centrales en la participación en la lucha armada de las mujeres, en una declaración que data de octubre 2013, esto es, casi un año antes de que en la Habana se instalara la subcomisión técnica de género, guerrilleras de las FARC-EP, en ese momento todavía mujeres combatientes, afirmaban que esta combinación de factores múltiples que pueden jugar un papel decisivo en el momento de la entrada a un grupo insurgente se conjuga, a su vez, con el carácter político de la decisión de participar en la lucha armada. En sus palabras: 
Fuimos empujadas a esta guerra cruenta, violenta y dolorosa; tuvimos el valor de acudir a las armas para defender a los desposeídos y a nosotras mismas. Seguimos combatiendo denodadamente en todos los escenarios posibles, buscando salidas a la confrontación sangrienta a la que nos ha sometido la oligarquía por más de medio siglo. Ser guerrilleras significa tomar la decisión de luchar, de asumir la responsabilidad por nuestros actos, de liberarnos de un destino preestablecido, de esos roles definidos por una sociedad injusta y excluyente. Nuestro ingreso a filas representa de por sí un acto de rebeldía y liberación; es hacer parte de un colectivo donde ser hombre o mujer está rebasado por la condición de combatientes revolucionarios por un mundo justo (Guerrilleras de las FARC-EP, 2013, s.p.).

\section{Ser combatientes y luchadoras por la paz: transformación de conflictos en las experiencias de las mujeres dentro de los grupos armados insurgentes}

Como queda evidenciado en el apartado anterior, las mujeres excombatientes no evocan la paz como uno de los motivos que incitó o que sustentó su decisión de entrar y/o de permanecer dentro de un grupo armado insurgente. Esto, en principio, no tiene nada de sorprendente, pues la pertenencia a un grupo armado obedece, entera o mayoritariamente, a las dinámicas de la guerra y no, evidentemente, a aquellas de un contexto "de paz".

Esto implica, por supuesto, que si entendemos la paz en un sentido negativo, esto es, retomando a J. Galtung (1969), "como la ausencia de violencia directa y más específicamente como la ausencia de guerra o conflictos negativos" (citado en Zapata, 2009, p. 13), la militancia en los grupos armados subversivos, motivada por cualquier razón o cuando ocurre como consecuencia el reclutamiento forzado, está en clara contraposición y exclusión con respecto a la paz. Si el propósito de la paz (negativa) es que cesen las hostilidades o que se acabe con la guerra (por cualquier medio), es evidente que hacer parte de un grupo guerrillero y participar de la lucha armada, no podría, de ninguna manera, constituir un paso hacia la paz.

Sólo que las cosas en la práctica son mucho más complejas. Y afortunadamente es así. Para ganar en complejidad, considero que es necesario expandir la idea de la paz, de la construcción de la paz, y darle otros contenidos. Siguiendo al mismo Galtung, es importante pensar a la paz en positivo y ya no solo en negativo, de modo que la paz vaya más allá de la ausencia de violencia directa y se piense en clave de justicia social. "Esta visión exige la existencia de estructuras políticas, sociales y económicas que permitan una distribución equitativa del poder y el acceso a los recursos" (Zapata, 2009, p. 13). En otros términos, la paz positiva no sólo no se restringe a la ausencia de violencia física, sino que, además, "atiende" a otras formas de violencia que no necesariamente cobran la forma de bolillos, granadas, manotazos, puñales, pero que, todas ellas, menoscaban en bienestar y las posibilidades de los seres humanos y de las sociedades en conjunto (y esto, sin hablar de las formas de vida no humanas que son violentadas con frecuencia en nuestras sociedades).

Así, la paz positiva se piensa en términos de ausencia de violencias estructurales que actúan como pilares de la injusticia y la exclusión social, y de construcción de otros mundos posibles. Al respecto, vale la pena traer a colación la siguiente reflexión de Vera Grabe, excombatiente del M-19 y directora de la Corporación Observatorio para la Paz:

Este enfoque de la paz tiene que ver entonces con
muchas paces, como la paz que se construye desde
los oprimidos, las mujeres, la paz con la naturaleza,
la paz en los espacios cotidianos; y la paz que im-
plica otra mirada como es la no-violencia, o la paz
imperfecta [...] No se trata de una "paz positiva" en
oposición y como superación de la violencia estruc-
tural, sino en positivo: una paz que se construye,
que es real (Grabe, 2017, pp. 142-413).

Vemos pues, que la paz entendida positivamente no refiere sólo a la ausencia de guerra, violencia directa, confrontaciones armadas, incluso de violencias estructurales, sino que es sobre todo creación, construcción, transformación. Hay, además, un elemento muy importante en esta concepción de paz y es el valor que se otorga al conflicto: éste no es entendido como un mal, como un fenómeno que deba ser resuelto de una vez y para siempre, extirpado como un tumor (social), sino que, por el contrario, 
es pensado como un motor social, como una fuente de movimiento, de reflexión, de acción.

En ese sentido, en este texto y a propósito de la participación de las mujeres en la lucha armada en clave de construcción de paz, prefiero optar por hablar de transformación y no de resolución de conflictos pues, como lo anota María Zapata, la perspectiva de la resolución de conflictos "enfatiza el desarrollo de estrategias y habilidades para terminar el conflicto y sus efectos destructivos, [...] [de modo que] trae el mensaje implícito de que el conflicto es algo negativo que debe terminarse" (Zapata, 2009, p. 21). Esta perspectiva, sin embargo, no resuelve el "problema" de la relación aparentemente excluyente (y no con pocas razones) entre paz, transformación de conflictos y violencia (en el caso que me interesa, la violencia implicada en la lucha armada). Dicha relación de aparente exclusión contiene la gran paradoja que atraviesa esta reflexión: que, aparentemente, buscar la paz por medio de la guerra no es sólo contradictorio, sino prácticamente imposible; $\mathrm{y}$, sin embargo, puede que justamente haya sido la guerra el camino recorrido por muchas mujeres en su búsqueda siempre incesante por construir la paz y transformar la sociedad. A este respecto, puede resultar útil volver a Grabe quien afirma que:

Atreverse a hablar de cultura de paz emergente en una organización armada parece un contrasentido, porque ella es generadora de violencia. Pero si lo asumimos como una paradoja, podemos afirmar que en el ADN del Eme había vetas de paz, una cultura emergente de paz [...] Hablo acá de paz como superación de lógicas reduccionistas, simplistas, bipolares, entendiendo que la paz convive con la violencia, está en permanente diálogo y puja con ella. Por eso me atrevo a hablar de paz como cultura emergente: con, a pesar, y en medio de la violencia (Grabe, 2017, pp. 307-308).

Muy a tono con esta idea de una paz "positiva", esto es, que no necesariamente niega o es excluyente con la violencia, es posible pensar no sólo que la pertenencia a y la militancia dentro de un grupo armado puede ser, efectivamente, una iniciativa o un "motor" de una cultura de paz emergente, retomando a Grabe, sino que, además, la participación en la lucha armada puede, al menos en potencia, ser coherente con apuestas sociales de transformación de conflictos, entendida como:

Una forma de visualizar y responder al ir y venir de los conflictos sociales como oportunidades que nos da la vida para crear procesos de cambio constructivo que reduzcan la violencia e incrementen la justicia en la interacción directa y las estructuras sociales, y respondan a los problemas cotidianos en las relaciones humanas (Lederach, 2003, p. 14).

En efecto, la preocupación por la justicia social y por los problemas cotidianos que enfrentan (aún hoy) amplios sectores de la sociedad colombiana, a causa de las relaciones de opresión, desigualdad y exclusión social, estaban presentes en los motivos que algunas excombatientes valoraron en el momento de decidir participar de la lucha armada como combatientes en un grupo armado insurgente.

Quizás sin ninguna sorpresa, estas preocupaciones aparecen en los relatos o testimonios de las mujeres que avanzan motivos ideológicos para explicar su decisión de devenir combatientes. Así, por ejemplo, Sandra, una joven mujer excombatientes de las FARC-EP con la que pude conversar, fue clara al evocar la situación de injusticia que veía que sufrían los pueblos indígenas del Norte del Cauca para dar cuenta de su decisión de entrar a la guerrilla; se trata, para ella, de una injusticia que se concretaba, entre otros, en la expropiación de sus tierras y en el maltrato que recibían de la fuerza pública, situación que no se presentaba, en su opinión, entre la guerrilla y la población de esa zona del país:

El ejército siempre que llegaba era abusador, maltratador, siempre pues como haciendo uso de la fuerza con la gente y maltratando a la gente y diciendo pues, bueno, para el ejército y la policía, todos los que vivíamos en el campo y los indígenas, sobre todo de ese sector, todos éramos guerrilleros, entonces el trato era pues feo, difícil hacia la población civil (Sandra, comunicación personal, noviembre de 2013).

Asimismo, María Vásquez (2000), Vera Grabe (2000) y Leonor Esguerra (Claux, 2011) afirman, en sus relatos, que en el momento en que sus militancias como guerrilleras estaban empezando, 
ellas concebían la paz como un resultado de lo que podríamos llamar la trasformación de conflictos, económicos, sociales y culturales que aquejaba a la sociedad colombiana en las décadas de los 70's y los 80's (muchos de los cuales, quepa anotarlo, persisten todavía). Por ejemplo, Grabe (2000), en su libro autobiográfico, nos comparte un episodio que ella considera decisivo en términos de su entrada al M-19. Se trata de un viaje que realizó en el marco de sus estudios universitarios y sobre el cual escribe lo siguiente:

Recorrimos la región, visitamos y nos quedamos en las malocas de los indígenas, hablamos con ellos [...] Ahí estaba la síntesis del abandono: las barrigas hinchadas, las enfermedades producto de la desnutrición, el trabajo precario, el endeudamiento para adquirir los bienes de los blancos, la pérdida de la propia cultura, y además todos los niveles de racismo entre la misma gente, entre indígenas, mestizos y negros [...] La conclusión obvia era que sólo si cambiaban las estructuras sociales y políticas que sostenían y fomentaba estas situaciones, podía mejorar la vida de la gente. Eso significaba derrocar el sistema, y para ello no había otro camino que las armas. Después de recorrer la región, no me quedó la mínima duda (Grabe, 2000, p. 49).

Leyendo este pasaje, resulta bastante claro que tanto la interpretación de las violencias y los conflictos, incluyendo el conflicto armado, como la transformación de los mismos, pasando por la lucha armada, está anclada en razones de orden estructural. Nuevamente, la relación, en principio impensable, entre participación en la lucha armada, la transformación de los conflictos y la construcción de la paz puede cobrar sentido. De hecho, es posible pensar que los conflictos están en el centro de la justificación que algunas excombatientes encontraron para entrar y quedarse en la guerrilla durante varios años o, para ser más precisa, la intención y el proyecto de transformación de esos conflictos estarían en el centro del proyecto de lucha armada. Insistimos, como Grabe, en que se trata de una relación por lo menos paradójica en la que la guerra y las armas se presentan como un camino hacia la paz que encontraría su razón de ser en la imposibilidad de transformar los conflictos por vías no violentas y democráticas.
Solo a manera de ejemplo, con Leonor Esguerra, podemos afirmar que la paz, entendida entonces en su sentido positivo, siguiendo la distinción propuesta por Galtung, y la transformación de los conflictos (políticos, sociales, económicos y culturales), estuvieron en el centro de las reflexiones y proyectos que inspiraron y dieron lugar a la emergencia de varios grupos armados insurgentes en el país, como el ELN. Esguerra, en un pasaje de su libro (que es una biografía escrita por una de sus amigas cercanas), nos cuenta, a propósito de los inicios de esta guerrilla:

Fabio y otros muchachos, recién el triunfo de la revolución cubana, habían formado una brigada de jóvenes de todos los países para ayudar a Cuba y se habían ido allá, llenos de entusiasmo. Colaborando con los revolucionarios cubanos tuvieron una buena oportunidad de meditar sobre la situación colombiana y pensaron que no podían quedarse de brazos cruzados [...] el 7 de enero de 1965 [...] por primera vez en su historia, el ELN tomó un pueblo: el pueblito de Simacota, en el departamento de Santander. Allí proclamaron que se había creado el Ejército de Liberación Nacional para buscar la libertad de todos los colombianos y la eliminación de toda discriminación por raza, sexo, color, origen social o creencias religiosas (Claux, 2011, pp. 192-194).

Vemos que la intención de transformar los conflictos que subyacen a diversas formas de discriminación no constituyen un elemento menor en términos de los propósitos del desarrollo de la lucha armada en el país, sino que, de hecho, es central tanto en las reivindicaciones de los grupos insurgentes como en la pertenencia de algunas combatientes a los mismos. Esto no significa, sin embargo, que exista una homogeneidad de los proyectos y las plataformas ideológicas de los grupos guerrilleros ni de las aspiraciones que las mujeres que hicieron parte de los mismos podían movilizar como parte fundamental de sus militancias. En efecto, es posible encontrar referencias recurrentes a la búsqueda de la "justicia social" sin que este concepto agrupe un conjunto de propuestas y proyectos particulares a las insurgencias en el país.

Angelika Rettberg afirma que la "justicia social", asunto que hace parte de las propuestas de paz muchas veces reclamadas por las guerrillas, es un tema 
general e intangible (2006). La misma autora sostiene, sin embargo, que con el paso de los años ese tema y otros con las mismas características (la cultura de paz, la convivencia pacífica) han sido complementados y han ido ganando en especificidad. Al respecto, el análisis propuesto por Vera Grabe frente a los lugares que ocupó la paz en las apuestas políticas y militares del M-19 puede ser muy esclarecedor. Para ella, este movimiento insurgente tenía, desde sus inicios, "vetas de paz", es decir, que la construcción de la paz estaba presente dentro de las inquietudes de esta guerrilla desde el momento de su creación, aun cuando no tuviera esa denominación, ese nombre. Pero, de manera más precisa, Grabe sostiene que desde 1980, el M-19 se articuló alrededor de una propuesta de paz que guió tanto su actividad política como militar. Dicha propuesta empieza a tomar forma en medio de la toma a la Embajada de República Dominicana y contenía tres grandes puntos o reivindicaciones: 1) amnistía para los prisioneros políticos; 2) derogatoria del Estatuto de Seguridad y 3) el Diálogo Nacional (Grabe, 2017, p. 427).

La propuesta de paz que expone Grabe resulta importante por varias razones; la primera de ellas, es que la insurgencia, en concreto el M-19, empieza a hablar de paz y ya no sólo de justicia social o de eliminación de las discriminaciones; adicionalmente, no sólo se trata de enunciar la paz como una bandera vacía (que ha sido, y quizás cada vez más, retomada por todos los sectores políticos tanto para plantear propuestas como para desprestigiar a quienes consideran sus adversarios en la arena pública), sino de una paz que, en opinión de Grabe, se mueve en un doble sentido, a saber, en términos de cambios y transformaciones sociales, así como de la eliminación de medidas antidemocráticas que, para poder concretarse, requería de diálogo.

Llegadas a este punto, creo que, aunque parezca simple en principio, hablar de paz en términos de diálogo resulta tremendamente potente. Esta potencia proviene del hecho que el diálogo propuesto desde esta insurgencia desbordaba la "negociación" entre el Estado y un grupo armado, sino que se trataba de un diálogo

[...] entre el pueblo y el Estado. Entre autoritarismo y democracia. Bateman [Comandante General del
M-19 hasta su muerte en 1984] sacó la paz del debate entre élites del establecimiento y élites de la subversión [...] Propuso una paz posible, porque se trataba de algo tan simple como dialogar: Colombia necesitaba escucharse y dialogar (Grabe, 2017, p. 431).

Esto no implica, de ninguna manera, que las propuestas de paz hayan encontrado exclusivamente en las insurgencias, como el M-19, los espacios de su creciente concreción. Implica, más bien, que los proyectos de las insurgencias y las acciones que sus militantes, hombres y mujeres, desarrollaban tanto en el plano político como el militar, contribuyeron a la creación de lugares de diálogo, de escucha y formulación de propuestas más o menos específicas, que llenan de contenido tanto a la "justicia social" como a la "paz" misma. Resulta particularmente pertinente el siguiente fragmento del texto de Grabe que hemos venido tratando, en el que habla del Comando de Diálogo del M-19 que buscaba tomar contacto con el gobierno colombiano, organizar encuentros en plazas públicas para explicar la tregua armada del M-19 y organizar el Gran Diálogo Nacional:

Bateman había hablado del Diálogo como "un gran sancocho nacional", es decir un potaje en el que se encontraran todos los sectores, las propuestas más diversas, un espacio participativo de interlocución en un país no acostumbrado a dialogar y a escucharse, y que las propuestas que emanaran de la gente se convirtieran en propuestas de reforma y cambio, a las cuales se comprometería el gobierno con el concurso de todas las fuerzas participantes del Diálogo. En el mismo sentido, cuando varios miembros del equipo de Diálogo sugerimos elaborar propuestas y programas, Álvaro Fayad, uno de los comandantes del M-19, fue enfático: "Nosotros generamos el escenario y proponemos una manera, pero las propuestas las hace mucho mejor la gente que conoce los temas y tienen conocimiento técnico, no vamos a suplantar a nadie, somos propiciadores del Diálogo (Grabe, 2017, p. 471).

Así pues, es preciso insistir en que los contenidos precisos de lo que es la paz, de las propuestas concretas para la transformación de los conflictos en el país, no necesariamente han emergido, o en todo caso no de manera exclusiva, de las insurgencias armadas. Más aún, con esto no queremos decir 
que no haya obstáculos y limitaciones importantes en términos de la construcción de paz y de la transformación de conflictos desde la lucha armada y desde la participación en los proyectos insurgentes. Sin embargo, me parece preciso sostener que tanto la paz como sus contenidos han sido importantes en términos de la lucha armada desarrollada por diversos grupos subversivos y han estado presentes en las motivaciones que inspiraron y sustentaron la participación de algunas mujeres en esos espacios. Las palabras de Cristina, excombatiente del M-19, son bastante claras en este sentido: "Yo creo que todo momento [...]; aun haciendo la guerra y aun en búsqueda de cosas, siempre pensando en la paz; o sea eso no... eso no es que un momento empezamos a buscar la paz, no, siempre, desde siempre..." (Cristina, comunicación personal, noviembre de 2013).

\section{La experiencia excombatiente de las mujeres en clave de construcción de paz}

Según Londoño y Nieto (2007) y Villarraga (2015), a lo largo de la década de 1990, nueve grupos insurgentes o alguna de sus facciones, negociaron con el gobierno colombiano y pactaron su desmovilización colectiva: el M-19 (1990); el Ejército de Liberación Popular (EPL, 1991) (parcialmente desmovilizado), el Movimiento Armado Quintín Lame (MAQL, 1991), el Partido Revolucionario de los Trabajadores (PRT, 1991), los Comandos Ernesto Rojas (CER, 1992), la Corriente de Renovación Socialista (CRS, facción del ELN, 1994), el Frente Francisco Garnica de la Coordinadora Guerrillera (FFG, 1994), las Milicias de Medellín (1994) y el Movimiento Independiente Revolucionario, Comandos Armados (MIR-COAR, 1998).

Frente a este conjunto de negociaciones, es importante destacar el papel que tuvieron en la posibilidad y la concreción de la Asamblea Nacional Constituyente de 1991. A pesar de las múltiples transformaciones que ha vivido la carta constitucional que de ella emanó, cabe pensarla en términos de una reforma institucional y una apertura democrática que, con todas sus limitaciones, significó un cambio en la vida política del país. En ese sentido, cabe destacar que:
Un elemento clave de todas las negociaciones, incluidos los intentos fallidos con las FARC-EP, fue el debate sobre una posible reforma del sistema político. Todos los grupos guerrilleros propusieron, de alguna manera, convocar una especie de asamblea constituyente y/o destacaron reformas constitucionales como un paso necesario hacia una solución del conflicto armado. Mientras que el EPL y su ala política, el Partido Comunista de Colombia - Marxista Leninista (PCC-ML), habían estado exigiendo una asamblea constituyente desde 1984 (Villarraga 2009, 95; 2013, 37ss), la Junta Coordinadora Guerrillera Simón Bolívar (CGSB), que agrupaba a la mayoría los grupos guerrilleros, FARC-EP y ELN entre ellos, declaró en octubre de 1990 que una Asamblea Nacional Constituyente podría convertirse, posiblemente, en la herramienta de cambio político, si se basaba en un amplio consenso de todos los sectores de la sociedad - incluidos los grupos guerrilleros (CGSB 1990) (Rampf y Chavarro, 2014, p. 8).

Sobre estas negociaciones y su relación con la ANC de 1991, en clave de transformación de conflictos, es preciso volver sobre el final de la cita inmediatamente anterior, pues destaca la apuesta de varios grupos guerrilleros por plantear dicha asamblea (con ese nombre o no) como un escenario posible de apertura del sistema político y, más aún, de cambio político. Este cambio no podría provenir exclusivamente de las plataformas y reivindicaciones de las insurgencias, sino que requería de la participación de distintos sectores de la sociedad colombiana, cuyos intereses y propuestas podrían encontrar cabida en las discusiones de la ANC y, más aún, en la Constitución Política del país. Al respecto, María Vásquez nos dice:

En el contexto propiciado por la Constituyente, la ciudadanía ensayó maneras de entender y hacer efectiva la democracia política, económica y social, maduró reflexiones sobre el alcance de los cambios que vendrían, y hasta imaginó otras maneras de acercarse a una negociación con la insurgencia que permanecía en armas, al punto de ilusionarse con la posibilidad de una paz definitiva (Vásquez, 2014, s.p.).

De este modo, la ANC fue pensada, desde las organizaciones subversivas, como una posibilidad para debatir los problemas a los que hacía frente el 
país y, más importante aún, para pensar esos problemas en términos de los conflictos que los subyacían para así procurar la construcción de herramientas constitucionales que viabilizaran ya fuera su transformación o su resolución. No es de mi interés (en gran parte porque no puedo hacerlo, no cuento con información ni herramientas suficientes) establecer si dicho propósito encontró buen puerto, en cambio, considero adecuado destacar de acuerdo con Angelika Rettberg, que

las negociaciones de paz con grupos insurgentes [...] generaron interés y estimularon atisbos de participación de la sociedad civil (Fernández, García-Durán y Sarmiento, 2004; Grabe, 2004; Nasi, 2003). Si bien éstas fueron negociaciones principalmente lideradas por los jefes de cada bando, representantes de la sociedad civil tuvieron asiento en las mesas de negociación. Más importante aún, muchos desmovilizados de estos grupos se convirtieron en activistas de la paz, nutriendo las filas de las nacientes como también de futuras organizaciones promotoras de paz (Rettberg, 2006, p. 19).

Esta afirmación parece coincidir con el camino que hemos venido explorando y que ha sido reivindicado por mujeres excombatientes en distintos escenarios, a saber, que las mujeres que hicieron parte de los grupos de guerrilla tenían apuestas políticas encaminadas a la transformación (y/o resolución) de los conflictos y la construcción de la paz. Dichas apuestas no se agotaron y no podrían haberse agotado en sus actividades dentro de las guerrillas, pues, de un lado, los conflictos que eran considerados dentro de las plataformas y programas de los grupos guerrilleros pudieron sufrir cambios a lo largo de los años (pensemos, por ejemplo, en la concentración de la tierra que si bien ha sido una constante en nuestra historia republicana, ha conocido una variedad de actores y de intereses que intervienen en ese conflicto en particular) y, por otro lado, porque es posible (y, en mi opinión necesario) pensar los conflictos como un elemento inmanente a la vida en sociedad, en comunidad, a la vida política. De modo que incluso si los conflictos que motivaron la participación de dichas mujeres en la lucha armada, de manera más o menos fuerte, pudieron tener cambios ("positivos" o "negativos"), esto no implica que todos ellos hayan sido resueltos o transformados, y mucho menos que hayan dejado de existir conflictos que justifiquen e impulsen acciones políticas por parte de las mujeres que hicieron parte de algún grupo subversivo.

Esto, por ejemplo, resulta claro en la postura que han asumido, en los últimos años, varias mujeres que hicieron parte de las FARC-EP y que actualmente son militantes de la Fuerza Alternativa Revolucionaria del Común (Farc). En efecto, en la primera tesis de mujer y género, citada anteriormente, podemos encontrar la reafirmación de las luchas anticapitalistas y antiimperialistas que atravesaron la acción político-militar de la guerrilla de las FARC-EP y, más aún, la "adopción” de nuevas luchas revolucionarias y críticas como, por ejemplo, aquellas referidas al patriarcado, el racismo y la homofobia (Farianas, 2017). Así pues, tenemos que, de un lado, las luchas "históricas" avanzadas como principios políticos en las FARC-EP no han sido resueltas de manera "definitiva", en tanto las luchas contra el capitalismo y el imperialismo siguen teniendo un lugar en los principios de las mujeres excombatientes de esa insurgencia, y, de otro lado, dichos principios se amplían y empiezan a generar reflexiones en torno a conflictos que antes ocupaban, cuando mucho, un lugar marginal dentro de la lucha armada.

El desarrollo de este tipo de reflexiones, centradas en relaciones de opresión y de exclusión que antes no ocupaban un lugar importante en la acción política de las mujeres (ex)combatientes, puede coincidir con el momento de la desmovilización colectiva del grupo armado o con la salida individual de las mujeres de la lucha armada. Las inquietudes y la militancia feminista que algunas mujeres excombatientes han forjado y desplegado, si bien hunde sus raíces en experiencias que pudieron haber antecedido u ocurrido en el marco de su participación en los grupos armados insurgentes, suelen tomar una forma más concreta y más relevancia en su accionar político, tras su salida de los mismos. De hecho, en el caso de las FARC-EP, las importantes discusiones que desarrollaron en materia de género y de lo que ellas mismas han nombrado como "feminismo insurgente" son, en palabras de Victoria Sandino, bastante recientes; más aún, ella sostiene que: 
Hay que decir que es un proceso que se inició en La Habana, porque lo que nosotras tenemos que decir es que había una práctica, que siempre luchamos por los derechos de las mujeres, pero no teníamos como una identidad o una línea feminista de referencia, porque eso también está ligado a los desarrollos de los movimientos sociales y revolucionarios y también a la relación que el movimiento revolucionario ha tenido con estos movimientos. Entonces nosotras hablábamos de los derechos de las mujeres, de la igualdad entre mujeres y hombres, pero no habíamos abordado el tema de la teoría feminista propiamente. Es a partir de La Habana que empezamos a hacer un estudio juicioso, concienzudo de todas estas teorías, y también el intercambio con las mujeres cubanas, intercambio con todas las mujeres que transitaron por Cuba a lo largo del proceso de paz, especialmente las mujeres colombianas. Eso nos llevó a declararnos, a muchas de nosotras, feministas $i Y$ por supuesto que yo estuve entre ellas! Todo este camino nos llevó no solamente a declararnos, sino también a construir nuestra propia reivindicación alrededor del feminismo desde nuestra práctica, identificar que esa práctica que habíamos tenido, pues no era otra cosa más que el feminismo insurgente (Paz, 2017, s.p.).

Ahora bien, esta situación puede encontrar asidero en una de las premisas recurrentes aportada por Grabe (2017) en su texto y por diferentes mujeres excombatientes, en el hecho que, para ellas, las armas constituían una herramienta en el (siempre inacabado) camino hacia la paz y no un fin en sí mismo. Y, evidentemente, las armas no son las únicas "herramientas" disponibles para andar la senda de la paz. De modo que muchas de las excombatientes que tuvieron como motivación (principal o no) la búsqueda de la justicia social y la paz, la han proseguido individual y colectivamente después de haber dejado la lucha armada. Al respecto, resulta pertinente traer a colación el cálculo que hace Alix Sálazar, excombatiente del M-19 y activista por la paz, quien considera que el $80 \%$ de las mujeres que hicieron parte de grupos armados (insurgentes) trabaja o ha trabajado por la paz (Sánchez-Blake, 2012b). Y esto porque, como veremos a continuación en palabras de E. Sánchez-Blake, las búsquedas de la paz y de la justicia social siguen siendo indisociables y ocupando un lugar central en las actividades y trabajos de las excombatientes en el país, ya que tienen un sentir colectivo expresado en distintas formas por varias excombatientes: no puede existir paz sin justicia social. De ahí que la gran mayoría de las excombatientes trabajen por la paz en sus múltiples dimensiones. Tanto María Eugenia Vásquez como Vera Grabe, dos de las mujeres que tuvieron mayor liderazgo en el M-19, trabajan activamente por la paz. Vásquez ha estado vinculada con proyectos de reinserción y de desplazados durante los pasados diez años, así como con aportes a talleres de recuperación de la memoria y proyectos de vida de las mujeres víctimas y agentes de la violencia. Grabe ha promovido desde el Senado proyectos de ley por la equidad de la mujer y actualmente trabaja como directora del Observatorio para la paz. Grabe es la gestora y promotora del concepto "pedagogía de paz", una iniciativa tendiente a educar a la población desde las raíces para cambiar comportamientos sociales que generan violencia y construir nuevos escenarios sociales dentro de una cultura de paz (Sánchez-Blake, 2012a, p. 11).

Y no es extraño encontrar a más mujeres que, como ellas, están comprometidas en la búsqueda de la paz. Las apuestas son, además y afortunadamente, variadas y diversas. Sandra, por ejemplo, ha hecho parte de varios grupos de personas desmovilizadas e, incluso, ha sido la promotora de varios de ellos. Entre otras, participó en la creación de una asociación de desmovilizados y desmovilizadas para impulsar el acceso de estas personas a la educación superior. Además, ha participado activamente de la Mesa Distrital de Desmovilizados, una organización apoyada por la administración de la ciudad de Bogotá y cuyo propósito fue el de crear un espacio propicio para debatir alrededor de las condiciones de vida, sobre todo en términos laborales, de las personas desmovilizadas que habitaban en la capital del país.

Adicionalmente, hay iniciativas desde las mujeres excombatientes que han logrado articularse con otros espacios de mujeres que tienen apuestas de transformación de conflictos y construcción de paz. Por ejemplo, Taína Trujillo, quien hace parte activa de la Red Nacional de Mujeres Excombatientes de la Insurgencia y escribe periódicamente en la revista virtual La13, nos cuenta que tuvo la oportunidad de conocer y participar del encuentro de

Las Mujeres Mediadoras para la Paz [que] es una agrupación de lideresas que representan a diversas 
agrupaciones sociales de la geografía nacional, que buscan interceder en las dificultades propias de la vida en comunidades afectadas por el conflicto, a través de la implementación del diálogo y la participación de actores que son respetadas y respetados en las comunidades afectadas, para encontrar salidas colectivas que propicien la convivencia en paz. En el Putumayo trabajamos durante dos días, muy poco tiempo para conocernos mejor, pero el suficiente para comprender el temple que han logrado las mujeres de las tres regiones putumayenses frente al conflicto que viven en su territorio. Ellas, las Tejedoras de vida, han jugado un papel importante para frenar la violencia local, han hablado con todos los actores armados y han logrado ser tan respetadas como escuchadas. A ellas les han devuelto personas secuestradas en el pasado, han sido activas para salir adelante después de masacres perpetradas en sus territorios de manera que han ejercido la mediación sin que se hayan dado cuenta, como nos ha sucedido a la mayoría de las mujeres que llegamos a trabajar hace un año en la formación como mediadoras que empieza confluir en una organización no violenta y que en este taller del Putumayo se le ha nombrado como Mujeres Mediadoras para la Paz (Trujillo, 2015, s.p.).

Para cerrar este apartado me parece pertinente destacar, precisamente, la existencia y las acciones desarrolladas por la Red Nacional de Mujeres Excombatientes de la Insurgencia, una iniciativa excepcional de acción colectiva de mujeres excombatientes que se han organizado para agrupar distintos trabajos impulsados por mujeres que participaron de la lucha armada dentro de grupos subversivos y para reflexionar y desarrollar acciones colectivas por la paz en el país. Al inicio, se trató de un esfuerzo (un colectivo) de encuentro y diálogo alrededor de las experiencias de las excombatientes que buscaba, además, "reposicionar" dichas experiencias en la sociedad colombiana. En todo caso, como lo precisan Londoño y Nieto, el Colectivo expandió rápidamente sus objetivos, de modo que el trabajo de recuperación de la memoria individual y colectiva de estas mujeres (que sigue estando presente en sus trabajos) empezó a estar acompañado por actividades y proyectos entorno a la resolución del conflicto armado y la construcción de la paz (Londoño y Nieto, 2007, p. 89). Al respecto, Clara Inés Guerrero, una de las mujeres que pertenece y trabaja activamente en la Red nos permite entender esta amplitud por medio de estas bellas palabras, en uno de sus textos para la revista La13:

Desde donde estoy parada para proponer un camino hacia la paz, es la clave para comprender cada uno de los hilos del tejido que las mujeres hacemos con la paz. Por momentos hay hilos enredados, en otros manojos sueltos, en otros hilos cortos o demasiado largos, en fin... el tejido de las propuestas de hacer la paz es una gran colcha de retazos en crecimiento. Sembrar y tejer dos acciones que nos han marcado los roles y están en íntima ligazón en el oficio de cuidar y proteger la vida. Siembro y cosecho la paz para hilarla y tejerla.

Las múltiples definiciones de paz siempre están enmarcadas en contextos definidos. El nuestro es un proceso complejo, largo, saturado de violencias y con un tejido simbólico guiado por la retaliación. En tal sentido, en esta propuesta asumimos la paz -como respuesta a esta guerra infame- como una creación de armonía donde la justicia social y la inclusión sean maneras de ser; el bien común guíe a la política; y la libertad y el amor sean el motor del ser social e individual. Para ello son necesarias acciones en el presente que vayan creando y construyendo la paz (Guerrero, 2014, s.p.).

Tanto las acciones colectivas emprendidas desde la Red Nacional de Mujeres Excombatientes de la Insurgencia, como aquellas desarrolladas individual o grupalmente por mujeres que han hecho parte de distintos grupos subversivos, nos permiten constatar la persistencia, tanto de las inquietudes que muchas de estas mujeres tuvieron al decidir su participación en la lucha armada, relativas a conflictos estructurales de la sociedad colombiana, como de su intención, llevada a la práctica, de desarrollar acciones que permitan la transformación de esos conflictos.

\section{A modo de conclusión}

Como hemos visto a lo largo de este texto, la participación de las mujeres en la construcción de la paz y la transformación de los conflictos ha tenido lugar, incluso en los escenarios más "inesperados", incluida la lucha armada y la guerra. En efecto, he procurado demostrar que las mujeres en Colombia han hecho parte activa de los grupos subversivos como 
combatientes, hecho generalmente ignorado al considerar la guerra como un asunto de hombres en el que las mujeres sólo "pueden” ocupar roles pasivos. La visibilización de este hecho, si bien resulta insuficiente en términos de la construcción de análisis de género que nos permitan entender las vivencias (diferenciadas o no) de hombres y mujeres al interior de la lucha armada, resulta ser, en mi opinión, un paso imprescindible en este sentido, pues nos permite empezar a resquebrajar la creencia según la cual las mujeres no han jugado ningún rol en el desarrollo del conflicto armado. Así, pues, considero de suma importancia reconocer que muchas de ellas, experimentaron la confrontación armada y la utilización de las armas como un medio que les permitía buscar la paz y la justicia social. Sin embargo, y como lo vimos en la primera sección, el hecho de que las mujeres participaran de los grupos guerrilleros en el país no fue un proceso evidente. Cabe aclarar, sin embargo, que las vías que permitieron, o mejor que hicieron posible que las mujeres entraran a militar a los grupos armados subversivos (ya fuera como combatientes o de otra manera), variaron de manera muy significativa entre las diferentes guerrillas.

Adicionalmente, como he tratado de mostrar, cada mujer tiene una historia particular que constituye, necesariamente, una experiencia singular en términos de las maneras y las motivaciones de ingreso a la lucha armada. Esto cobra una particular importancia en la medida en que, como mencioné al inicio de este texto, mi interés no versa sobre la construcción de análisis que identifiquen la vivencia de la mujer excombatiente pues, muy al contrario, me parece vital asumir una postura que tenga en cuenta, evidencie y valore las distintas experiencias que han vivido las mujeres excombatientes, tan diversas como puedan ser. Es importante, en todo caso, resaltar que estas diversas experiencias tuvieron lugar en contextos específicos que, por ejemplo, estuvieron marcados en procesos de emancipación de las mujeres en la segunda mitad del siglo XX (con todas sus potencialidades y límites), así como por la polarización política, la movilización social y la represión estatal. Por ello, es posible considerar que reducir las explicaciones que nos ayuden a entender la participación de las mujeres en la lucha armada como combatientes a sus historias personales o al contexto, resulta, cuando menos, insuficiente. Por ello mismo, y teniendo en cuenta las diferencias entre los diferentes grupos guerrilleros (que han sido poco exploradas) antes mencionadas, podemos volver a Londoño y Nieto para reafirmar que se trata de una historia poco conocida y que sigue estando pendiente.

Ahora bien, he procurado concentrarme en lo que, en un intento de caracterización, podemos llamar los motivos ideológicos del ingreso y de la participación de las mujeres en los grupos subversivos. Esto porque varias mujeres excombatientes afirman que, desde el principio, su decisión de hacer parte de la lucha armada se explica, al menos parcialmente, por su convicción de la necesidad de transformación social y de luchas por la justicia social. Estas reivindicaciones se encontraban presentes tanto en las preocupaciones de estas mujeres como en la de los grupos armados en los que, finalmente, terminaron participando, pues los grupos subversivos nacen como intentos de cambios respecto de conflictos de orden político, económico y social, y posteriormente, algunos de ellos, desarrollan propuestas específicas en términos de la búsqueda de la paz. Al respecto, considero importante volver sobre la importancia que este reconocimiento puede tener en materia de los relatos sobre el conflicto armado colombiano desde un enfoque de género. En efecto, los relatos dominantes suelen desconocer, por una serie de motivos que desbordan los propósitos de esta conclusión, el carácter político de la lucha armada insurgente. Sin embargo, y dado que ésta suele ser pensada como un asunto de "hombres", es posible encontrar con frecuencia afirmaciones según las cuales esos guerreros tuvieron, al inicio de las guerrillas, propósitos políticos que fueron reemplazados paulatinamente con el paso de los años. Sin embargo, como las mujeres no son pensadas como partícipes de la lucha armada, los motivos políticos que pudieron animar su pertenencia a alguna insurgencia, suelen quedar en el más profundo olvido. No se trata entonces solamente de identificar uno de los efectos que el género, como relación social, tiene sobre las lecturas más difundidas del conflicto armado, sino de una puesta en evidencia de la falsedad de este efecto, a saber, que no es cierto que las mujeres no hayan participado 
del conflicto armado y que, de hacerlo, sucedió en el marco de relaciones sentimentales o por la mera coacción. En otros términos, se trata también de un esfuerzo por reconocer una transgresión o, cuando menos, un cuestionamiento del género como una relación social que, en principio, hace impensable la existencia misma de mujeres combatientes y militantes a favor de determinados proyectos políticos de transformación social.

Ahora bien, he procurado, gracias a las reflexiones de Vera Grabe y de varias excombatientes, mostrar que la paradoja "lucha armada-paz" puede constituirse como tal (y ya no como una exclusión irreversible y definitiva) si ampliamos la concepción que tenemos de paz y, en términos de Galtung, pasamos de pensar una "paz negativa" a imaginar y construir una "paz positiva". Esta última requiere, necesariamente, de la transformación de conflictos estructurales que adquieren múltiples expresiones, muchas de las cuales no se reducen a la confrontación directa y a la violencia física, pero que sí generan situaciones violentas y el menoscabo de la vida en las sociedades en cuestión. En efecto, se ha afirmado que tanto los grupos armados insurgentes, como las mujeres que participaron de ellos como combatientes, desarrollaron, por medio de la lucha armada, iniciativas de transformación de conflictos y de construcción de paz.

Al respecto, fue importante destacar que esta búsqueda de la paz pasó, al menos en momentos precisos, por el interés de generar diálogos entre sectores sociales diversos. Así, por ejemplo, encontramos que la Asamblea Nacional Constituyente de 1991, fue pensada, desde las insurgencias, como una oportunidad para que los sectores marginados pudieran expresarse, plantear propuestas y, así, dotar de sentido y de contenido a la paz y a la justicia social. Resultó igualmente importante evidenciar que el camino de búsqueda de la paz de estas mujeres ha encontrado nuevas vías en sus experiencias como excombatientes. En efecto, sus reflexiones, acciones y proyectos para contribuir con la transformación de la sociedad colombiana y la construcción de otras realidades, de otros mundos, siguen estando presentes en sus cotidianidades y en sus sueños.

Al respecto resulta preciso indicar que la transformación de conflictos, tal y como la he descrito en este texto, incluye una variedad de fenómenos sociales de opresión y explotación ciertamente amplia. En todo caso, cabe resaltar que uno de los ejes de dichos fenómenos que está presente en las experiencias excombatientes de varias mujeres con quienes he tenido la oportunidad de conversar o a quienes he podido leer, y no tanto así en sus experiencias combatientes, es el género como relación social. En efecto, como procuré mostrarlo, las luchas antipatriarcales y por la equidad de género están presentes en los proyectos políticos de algunas mujeres excombatientes, pero no estaban presentes en los proyectos insurgentes de los grupos armados a los que pertenecieron y no constituían una preocupación central de sus militancias al interior de los mismos.

Ciertamente, en este texto, sólo hemos enunciado y explorado un poco algunos aspectos implicados en la participación de las mujeres en el conflicto armado en el país y de la relación entre sus vivencias, la transformación de los conflictos y la construcción de la paz. Encontrar los caminos más adecuados para acercarse a estas experiencias, a su complejidad e inmensa riqueza, constituye un reto y una pregunta constante de difícil resolución. En todo caso, este texto buscaba resaltar el carácter político de las experiencias de las mujeres excombatientes y, sobre todo, de sus preocupaciones y esfuerzos por desarrollar iniciativas de construcción de paz en un país como Colombia, en el que a pesar de que las embestidas de la opresión y la violencia no cesan, contamos con la inmensa fortuna de tener a sectores populares, a movimientos sociales, a organizaciones de mujeres diversas que no se rinden ante la injusticia y que se saben actrices de primer orden en la construcción de una sociedad diferente.

\section{Referencias bibliográficas}

Bartra, Eli. (2010). Acerca de la investigación y la metodología feminista. En Norma, Blazquez; Fátima, Flores y Maribel, Ríos (Coords.), Investigación feminista: epistemología, metodología y representaciones sociales (pp. 67-77). México: Centro de Investigaciones Interdisciplinarias en Ciencias y Humanidades y Centro Regional de Investigaciones Multidisciplinarias, Facultad de Psicología, Universidad Nacional Autónoma de México. 
Boutron, Camille. (2012). La 'Terroriste', la 'Milicienne' et la 'Policière': implication des femmes dans la violence armée au péro. En C. Cardi y G. Pruvost (Coords), Penser la violence des femmes (pp. 138154). Paris: Éditions La Découverte.

Cardi, Coline. y Pruvost, Genevieve. (2012). Introduction Générale. En Penser la violence des femme (pp. 13-64). Paris: Éditions La Découverte.

Claux, Ines. (2011). La Búsqueda. Testimonio de Leonor Esguerra. Bogotá: Aguilar.

Corporación Humanas. (2015). Memorias conversatorio 'Aprendizajes y retos para los procesos de desarme, desmovilización y reintegración de mujeres combatientes'. Bogotá: Corporación Humanas. Recuperado de http://www.humanas.org.co/archivos/170216_Memorias Evento_DDR 2015.pdf.

Esguerra, Juanita. (2013). Desarmando las manos y el corazón: transformaciones en las identidades de género de excombatientes (2004-2010). En Centro Nacional de Memoria Histórica, Desafios para la reintegración. Enfoques de género, edad y etnia (pp. 116-77). Bogotá: Centro Nacional de Memoria Histórica.

Farianas. (2017). Tesis de mujer y género para el Congreso Constitutivo del Partido. Recuperado de http://mujerfariana.org/images/pdf/TESIS-DE-GENERO.pdf.

Grabe, Vera. (2000). Del silencio de mi cello (Razones de vida). Bogotá: Observatorio para la Paz.

Grabe, Vera. (2017). La paz como revolución. Bogotá: Taller de Edición Rocca.

Guerrero, Clara Inés. (2014). Sembrar paz. La13, (1). Recuperado de http://www.revistala13.com/publicacion-n1/sembrar-paz.html.

Guerrilleras de las FARC-EP. (2013). Declaración pública. Recuperado de http://www.mujerfariana.org/ vision/declaraciones/75-declaracion.html.

Ibarra, María Eugenia. (2006). Transformaciones identitarias de las mujeres como resultado de su participación politica en las guerrillas y en las acciones colectivas por la paz en Colombia (Tesis doctoral). Facultad de Ciencias Políticas y Sociología, Universidad Complutense de Madrid, España.

Lara, Patricia. (2000). Las mujeres en la guerra. Bogotá: Planeta.

Lederach, John. (2003). Little book of conflict transformation: clear articulation of the guiding principles by a pioneer in the field. Virginia: Center for Justice and Peacebuilding.

Lelièvre, Christiane., Moreno, Graciliana. y Ortiz, Isabel. (2004). Haciendo memoria y dejando rastros. Encuentros con mujeres excombatientes del nororiente de Colombia. Bucaramanga: Fundación Mujer y Futuro.

Londoño, Luz. y Nieto, Yoana. (2007). Mujeres no contadas. Procesos de desmovilización y retorno a la vida civil de mujeres excombatientes en Colombia $1990-$ 2003. Medellín: La Carreta Social.
Paz, Ángela. (2017). El feminismo insurgente. Entrevista con Victoria Sandino. La13, (11). Recuperado de http://www.revistala13.com/publicacion-n11/elfeminismo-insurgente.html.

Rampf, David. y Chavarro, Diana. (2014). La Asamblea Nacional Constituyente de Colombia de 1991 - De la exclusión a la inclusión o ¿un esfuerzo en vano? Berlín: Berghof Foundation. Recuperado de https://bit.ly/2MB9qTa.

Rettberg, Angelika. (2006). Buscar la paz en medio del conflicto, un propósito que no da tregua: un estudio de las iniciativas de paz en Colombia (desde los años 90 hasta hoy). Bogotá: Universidad de los Andes.

Rodríguez, Alba. (2008). Entre el compromiso y la huida. Mujeres militantes en los grupos insurgentes colombianos. Amnis: Revue de Civilisation Contemporaine de l'Université de Bretagne Occidentale, (8). Recuperado de https://bit.ly/2PB8BqC.

Sánchez-Blake, Elvira. (2012a). De actores armadas a sujetos de paz: Mujeres y reconciliación en el conflicto colombiano. La Manzana de la Discordia, 7(2), 7-14. Recuperado de http://revistas.univalle.edu.co/index.php/ la_manzana_de_la_discordia/article/view/1558/1665.

Sánchez-Blake, Elvira. (2012b). Memoria de mujeres en el conflicto colombiano: reportajes, testimonios y nuevas semantizaciones. Tercer Milenio, (23). Recuperado de https://bit.ly/2PfW4tW.

Thomas, Florence. (1996). Mujer siglo XXI: hacia la construcción de un nuevo paradigma de feminidad. En S. Franco (Ed.), Colombia contemporánea (pp. 267-284). Bogotá: Instituto de Estudios Políticos y Relaciones Internacionales (IEPRI), Universidad Nacional de Colombia y Ecoe Ediciones.

Trujillo, Taína. (2015). Somos mujeres mediadoras para la paz. La13, (5). Recuperado de http://www.revistala13. com/somos-mujeres-mediadoras-para-la-paz.html.

Vásquez, María. (2014). Insurgentas: sujetas politicas en la construcción de paz. La13, (1). Recuperado de http:// www.revistala13.com/publicacion-n1/insurgentas.html.

Vásquez, María. (2000). Escrito para no morir. Bitácora de una militancia. Bogotá: Ministerio de Cultura.

Villarraga, Álvaro. (2015). Desmovilización y reintegración paramilitar. Panorama posacuerdos con las AUC. Bogotá: Centro Nacional de Memoria Histórica.

Zapata, María. (2009). Construcción de paz y transformación de conflictos. Bogotá: Universidad Nacional de Colombia.

\section{Fuentes primarias}

Entrevista con Cristina, excombatiente del M-19, noviembre de 2013.

Entrevista con Consuelo, excombatientes de las FARCEP, noviembre de 2013.

Entrevista con Lina, excombatiente de las FARC-EP, noviembre de 2013.

Entrevista con Sandra, excombatiente de las FARC-EP, noviembre de 2013. 


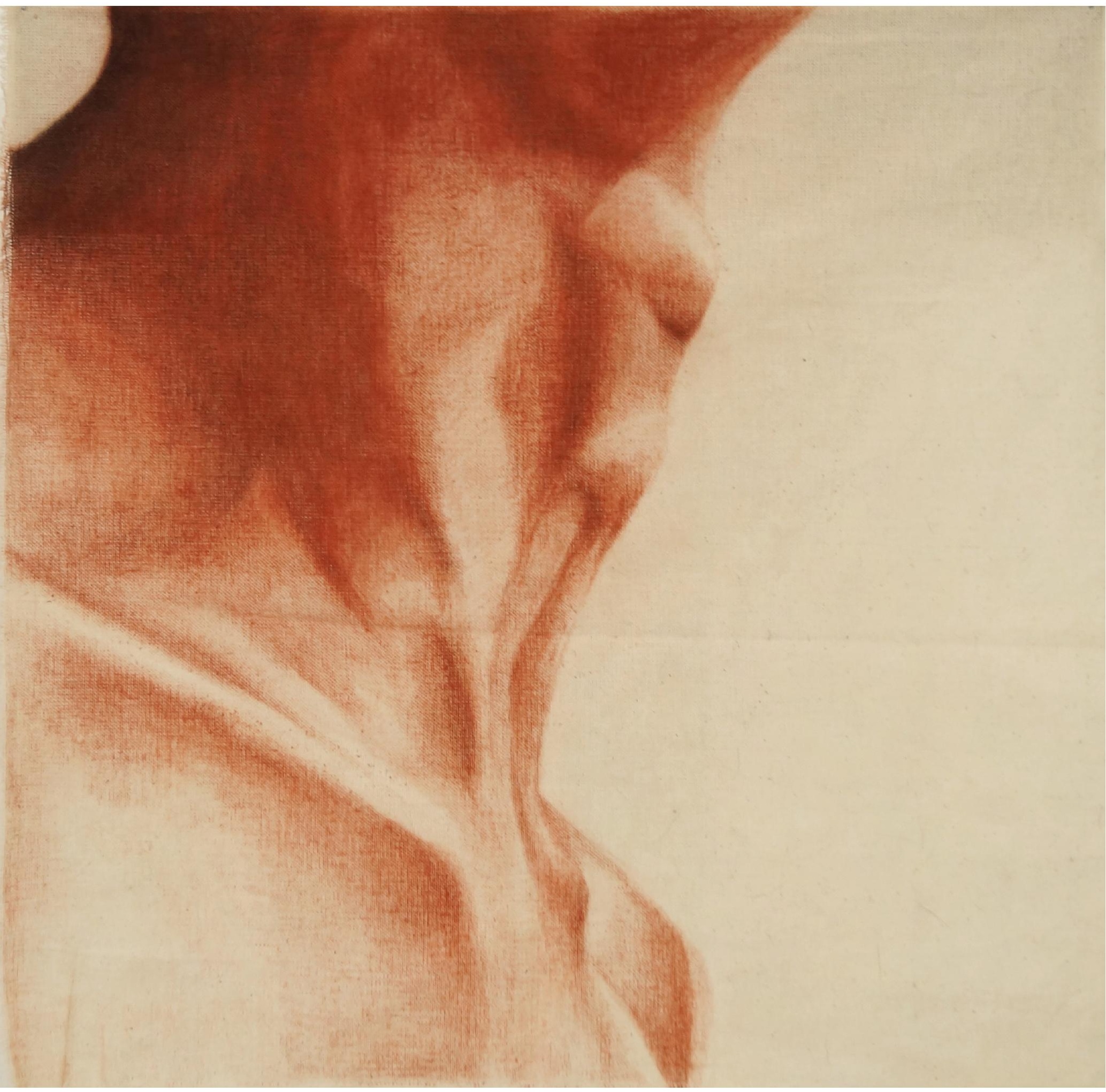

Imagen 2. Sin título (de la serie TRANS-ANATOMÍA)

Dimensiones: 54 x $58 \mathrm{~cm}$

Técnica: Lápices sanguina y sepia sobre lienzo

Año: 2018

Autor: Alie Galindez Poveda 